Rapid Communications

\title{
Uphill Transport of Rare-Earth Metals through a Highly Stable Supported Liquid Membrane Based on an Ionic Liquid
}

\author{
Fukiko Kubota, ${ }^{* \dagger}$ Yousuke Shimobori,* Yusuke Koyanagi, ${ }^{*}$ Kojiro ShimoJo, ${ }^{* *}$ Noriho KamiYa,* \\ and Masahiro GoтO*广
}

*Department of Applied Chemistry, Graduate School of Engineering, Kyushu University, Fukuoka 819-0395, Japan

**Division of Environment and Radiation Science, Nuclear Science and Energy Directions, Japan Atomic Energy Agency, Tokai-mura, Ibaraki 319-1195 Japan

\begin{abstract}
We have developed a highly stable supported liquid membrane based on ionic liquids (ILs) for the separation of rare-earth metals, employing $N, N$-dioctyldiglycol amic acid as a mobile carrier. The quantitative transport of $\mathrm{Y}$ and Eu through the membrane was successfully attained, and separation from metal impurities, Zn, was efficiently accomplished. A membrane stable enough for long-term operation was constructible from imidazolium-based ILs having a longer alkyl chain, such as octyl or dodecyl groups in an imidazolium cation.
\end{abstract}

(Received January 29, 2010; Accepted February 9, 2010; Published March 10, 2010)

Supported liquid membranes (SLMs) have attracted attention in industrial and analytical fields as a tool for the efficient separation and preconcentration of target species. However, the commercial applications of SLMs are limited because of the instability and short lifetime of the membrane. ${ }^{1}$

Ionic liquids (ILs), which are salts with low melting points, have unique properties not shared by conventional molecular solvents, such as high thermal stability and negligible vapor pressure. ${ }^{2}$ Furthermore physicochemical properties of ILs are extensively tunable. Therefore, water-immiscible ILs have a high potential for the construction of stable SLMs as an alternative to organic solvents for the membrane phase. Despite the advantages of ILs, there have been no reports on the application of IL-based SLMs for the separation of metals to date because no suitable combination of an IL and a carrier, which is dissolved in the membrane phase and binds a target metal ion from the feed phase, has been found. Extractants used for solvent extraction are usually diverted to carriers in the organic solvent system. ILs can, however, dissolve only a few extractants. Furthermore, the stripping of metals from ILs is generally very difficult when the extractants exhibit high extraction performance in ILs. ${ }^{3}$

Rare metals, including rare-earth metals, are indispensable elements for the high-tech industry, and are encouraged to be recycled from used products containing such metals. In this article, we consider the successful separation of $\mathrm{Y}$ and $\mathrm{Eu}$ from a solution containing a metal mixture, which is a main component of a phosphor for TV tubes, by using a liquid membrane based on ILs.

We employed newly synthesized $N, N$-dioctyldiglycol amic acid (DODGAA) ${ }^{4}$ as a carrier. $\quad N, N, N^{\prime}, N^{\prime}$-Tetra( $n$-octyl)diglycolamide (TODGA), which is a neutral tridentate ligand

$\dagger$ To whom correspondence should be addressed.

E-mail: f_kubotcm@mail.cstm.kyushu-u.ac.jp or m-goto@mail. cstm.kyushu-u.ac.jp with two carbamoyl groups connected by an ether chain, was reported to exhibit high affinity for rare-earth metals. ${ }^{5}$ DODGAA, which replaces one carbamoyl group of TODGA by a carboxy group, as shown in Fig. 1, is ionizable by dissociation of the carboxy group.

DODGAA and ionic liquids, 1-alkyl-3-methylimidazolium bis(trifluoromethanesulfonyl)imide (abbreviated as $\left[\mathrm{C}_{\mathrm{n}} \operatorname{mim}\right]\left[\mathrm{Tf}_{2} \mathrm{~N}\right]$, $n=4,8,12$ ) were synthesized as described previously. ${ }^{4}$ Extracting phases were prepared by dissolving DODGAA in the ILs, or $n$-dodecane containing $5 \mathrm{vol} \% 1$-octanol as a solubilizer. Aqueous feed phases were prepared by dissolving nitrate salts of $\mathrm{Y}, \mathrm{Eu}$ and $\mathrm{Zn}$ at $0.1 \mathrm{mM}$ each. The extraction equilibria were measured at $273 \mathrm{~K}$ by the conventional method. The stripping of metals from the extracting phase was carried out using nitric acid.

A supported liquid membrane was prepared by immersing a hydrophobic porous polyvinylidene fluoride film (Millipore, pore size $0.45 \mathrm{~mm}$ and thickness $125 \mu \mathrm{m})$ in $\left[\mathrm{C}_{\mathrm{n}} \mathrm{mim}\right]\left[\mathrm{Tf}_{2} \mathrm{~N}\right]$ or $n$-dodecane containing DODGAA. A transport experiment was performed using a glass cell unit which held the membrane (effective area $5 \mathrm{~cm}^{2}$ ) between two independent $55 \mathrm{~mL}$ compartments for the feed phase and the receiving phase. Samples were periodically withdrawn from the two phases, and the metal concentrations were measured by ICP-AES.<smiles></smiles>

Fig. 1 Molecular structure of $N, N$-dioctyldiglycol amic acid (DODGAA). 

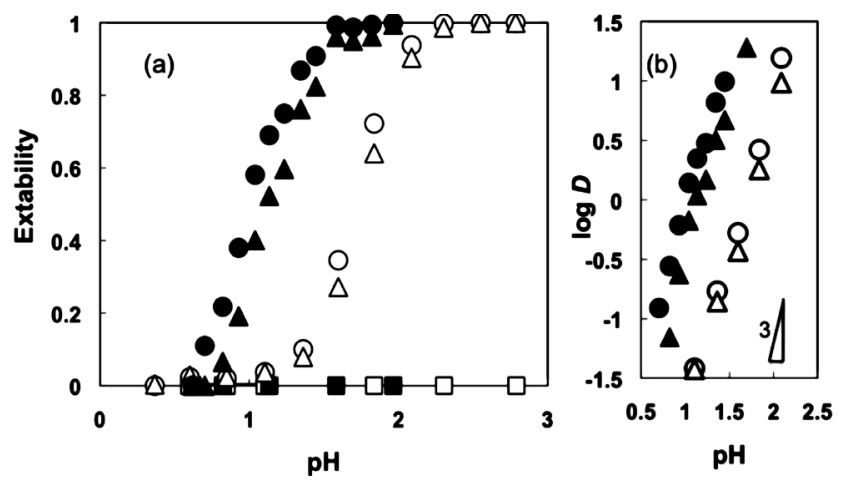

Fig. 2 Extraction behavior of $\mathrm{Y}^{3+}$ (circles), $\mathrm{Eu}^{3+}$ (triangles) and $\mathrm{Zn}^{2+}$ (squares) with DODGAA in $\left[\mathrm{C}_{4} \mathrm{mim}\right]\left[\mathrm{Tf}_{2} \mathrm{~N}\right]$ (closed symbols) or in n-dodecane (open symbols) systems. (a) Extractabilies of metal ions as a function of the aqueous-phase $\mathrm{pH}$. (b) Plots of $\log D$ versus $\mathrm{pH}$. Aqueous phase: $0.1 \mathrm{mM}$ each of $\mathrm{Y}^{3+}, \mathrm{Eu}^{3+}$ and $\mathrm{Zn}^{2+}, 1 \mathrm{M} \mathrm{HNO}_{3}-0.1 \mathrm{M}$ $\mathrm{CH}_{3} \mathrm{COOH}$. Extracting phase: $10 \mathrm{mM}$ DODGAA.

Figure 2(a) shows the extraction behavior of the metal ions from the aqueous phase to the $\left[\mathrm{C}_{4} \operatorname{mim}\right]\left[\mathrm{Tf}_{2} \mathrm{~N}\right]$ phase as a function of the equilibrium $\mathrm{pH}$ in the aqueous phase, along with that to the $n$-dodecane phase. Extractabilities $\left(\left[\mathrm{M}^{3+}\right]_{\text {org }} /\left(\left[\mathrm{M}^{3+}\right]_{\text {aq. }, 0}\right)\right.$ of $\mathrm{Y}$ and $\mathrm{Eu}$ to the IL phase were greatly enhanced compared to that of the organic solvent, whereas a metal impurity, $\mathrm{Zn}$, was not extracted to either of the extracting phases under the present experimental conditions. The high extraction ability and selectivity of DODGAA for $\mathrm{Y}$ and Eu are greatly attributed to the molecular structure created by the tridentate diglycol amic acid frame, because the extractabilities of $\mathrm{Y}$ and Eu were as low as that of $\mathrm{Zn}$ when the conventional carboxylic acid, versatic acid 10, was used as the extractant. Linear dependency with slopes of nearly 3 were obtained in logarithmic plots of the distribution coefficient $D\left(\left[\mathrm{M}^{3+}\right]_{\text {org }} /\left(\left[\mathrm{M}^{3+}\right]_{\text {aq }}\right)\right.$ versus the DODGAA concentration or the $\mathrm{pH}$ for the rare-earth metals (Fig. 2(b)). It was obvious that the extraction was mediated by proton exchange for a metal ion in the IL system, as in the organic solvent system. ${ }^{4}$ The stripping of metal ions, which was difficult in the IL-containing TODGA system, was readily completed by using an acid solution, such as nitric acid at around $1 \mathrm{M}$.

The transport of $\mathrm{Y}$ and $\mathrm{Eu}$ from aqueous feed mixtures also containing $\mathrm{Zn}$, was examined. Figure 3 shows the transport behavior of metal ions through the SLM based on $\left[\mathrm{C}_{8} \mathrm{mim}\right]\left[\mathrm{Tf}_{2} \mathrm{~N}\right]$ from the aqueous feed phase (initial $\mathrm{pH} 4$ ) to the receiving $1 \mathrm{M}$ nitric acid phase. As shown in Fig. 3, Y and Eu were selectively extracted, leaving $\mathrm{Zn}$ in the feed phase, and were also simultaneously stripped without accumulation in the membrane phase. Quantitative transport was successfully achieved within $40 \mathrm{~h}$ under the experimental conditions used, and the $\mathrm{Y}$ and Eu could be completely separated from the metal impurity, Zn. The membrane was stable even after $120 \mathrm{~h}$. SLM operation was also possible by using $\left[\mathrm{C}_{12} \operatorname{mim}\right]\left[\mathrm{Tf}_{2} \mathrm{~N}\right]$. In contrast, the concentrations of metal ions including $\mathrm{Zn}$ in the two aqueous phases became uniform within $80 \mathrm{~h}$ when $\left[\mathrm{C}_{4} \operatorname{mim}\right]\left[\mathrm{Tf}_{2} \mathrm{~N}\right]$ was used as the membrane phase. This was caused by water penetration accompanying proton penetration through a membrane made up of $\left[\mathrm{C}_{4} \operatorname{mim}\right]\left[\mathrm{Tf}_{2} \mathrm{~N}\right]$, which is much more hydrophilic than the other two ILs. ${ }^{6}$ Furthermore, the

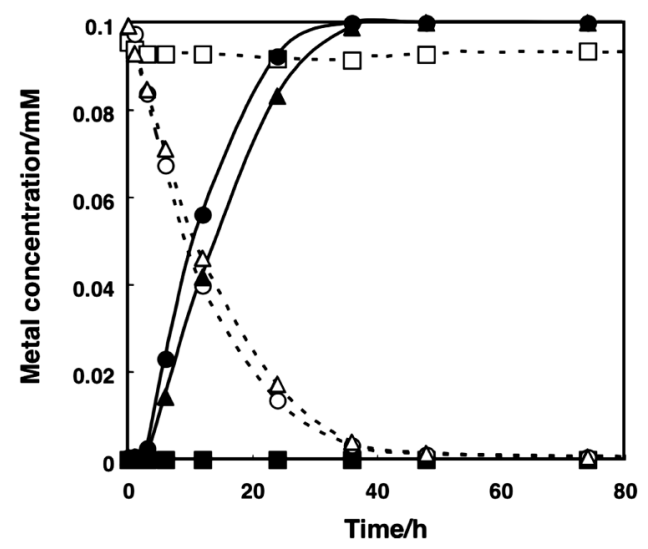

Fig. 3 Time courses of metal ion concentrations in the feed (open symbols) and receiving (closed symbols) phases during IL-based SLM operation. Feed phase: $0.1 \mathrm{mM}$ each of $\mathrm{Y}^{3+}$ (circles), $\mathrm{Eu}^{3+}$ (triangles), and $\mathrm{Zn}^{2+}$ (squares), $\mathrm{pH}$ 4. Receiving phase: $1 \mathrm{MHNO}_{3}$. Membrane phase: $\left[\mathrm{C}_{8} \mathrm{mim}\right]\left[\mathrm{Tf}_{2} \mathrm{~N}\right]$ containing $10 \mathrm{mM}$ DODGAA, $273 \mathrm{~K}$.

other two ILs may remain more stably in the membrane pores than the $\left[\mathrm{C}_{4} \mathrm{mim}\right]\left[\mathrm{Tf}_{2} \mathrm{~N}\right]$, because the ILs having longer alkyl chains in the imidazolium cation were a little more viscous (data not shown). Membranes impregnated with an organic solvent, such as $n$-dodecane, were also not able to withstand the operation, as in the case of the $\left[\mathrm{C}_{4} \mathrm{mim}\right]\left[\mathrm{Tf}_{2} \mathrm{~N}\right]$ system.

The uphill transport of $\mathrm{Y}$ and $\mathrm{Eu}$ was successfully achieved through a supported liquid membrane using $\left[\mathrm{C}_{8} \mathrm{mim}\right]\left[\mathrm{Tf}_{2} \mathrm{~N}\right]$ or $\left[\mathrm{C}_{12} \mathrm{mim}\right]\left[\mathrm{Tf}_{2} \mathrm{~N}\right]$ as a membrane solvent with acidic DODGAA as the carrier. It was demonstrated that a highly stable and efficient liquid membrane system can be constructed by choosing a suitable ionic liquid and a compound well designed as a carrier for the ionic liquid and the target metal ions. This is the first application of an SLM based on ionic liquids to the successful separation of metal ions.

\section{Acknowledgements}

This work was supported by Grants for Research and Technology Development on Waste Management (K2173) from the Ministry of Environment.

\section{References}

1. F. Kubota and M. Goto, Solvent Extr. Res. Dev., Jpn., 2005, $12,11$.

2. R. Liu, J. F. Liu, Y. G. Yin, X. L. Hu, and G. B. Jiang, Anal. Bioanal. Chem., 2009, 393, 871.

3. K. Kidani, N. Hirayama, and H. Imura, Anal. Sci., 2008, $24,1251$.

4. K. Shimojo, H. Naganawa, J. Noro, F. Kubota, and M. Goto, Anal. Sci., 2007, 23, 1427.

5. K. Shimojo, K. Kurahashi, and H. Naganawa, Dalton Trans., 2008, 5083.

6. L. Ropel, L. S. Belveze, S. N. V. K. Aki, M. A. Stadtherr, and J. F. Brennecke, Green Chem., 2005, 7, 83. 